\title{
Location-Based Knowledge Handover Optimization (LBKHO) Algorithm for mobile Network
}

\author{
Nagwan Abdel-wahab Mohamed Khair ${ }^{1}$, Ashraf GasimElsid², Amin Babiker \\ $\mathrm{A} / \mathrm{Nabi}^{3}$ \\ ${ }^{I}$ (Department of Data and Communication Network, Al Neelin University/ Faculty of Engineering, Khartoum, \\ Sudan. \\ ${ }^{2}$ (Department of Electronics Engineering, Collage of Engineering, Sudan University and Faculty of \\ Telecommunication and Space Technology, Future University, Khartoum, Sudan) \\ ${ }^{3}$ (Department of Communication Engineering, Al Neelin University/ Faculty of Engineering,
} Khartoum, Sudan.)

\begin{abstract}
Handover is a very important process in any mobile communication network because it allows the call continuation with high mobility and to supply Quality of Service $(Q o S)$ to the users. However the handover increases the signaling load in the network and increase the mobile battery consumption. Location based service offered a great opportunity for application development in the mobile field. In this paper LocationBased Knowledge Handover Optimization algorithm (LBKHO) is proposed, the location based knowledge is used to improve the network performance by reducing the number of handover request, which reduces the signaling load in the network. From our the simulation results show that the proposed algorithm (LBKHO) has reduced the number of handover requests and the number of failed handovers, and when compared with the model (Adaptive Handover Initialization Region) proposed in a previous study, found that requests for handover in the proposed in our algorithm much less. Which reduces the signaling load in the network so that network performance can be improved.
\end{abstract}

Keywords: Cellular Network, Location-Based, Handover Optimization, Horizontal Handover, Cell Breathing

\section{Introduction}

The most important characteristic of mobile communications systems has provided services at anytime and anywhere for the fixed and mobile users with different speeds within the area of coverage. So service providers in those systems always attempt to provide high quality services using different wireless communication technologies, but in despite of that, there are techniques when the using is increasing could increase the signaling load in the network also may increase the pressure on the system. On the other hand the system could not dispense with it, such as the handover process because its existence can guarantee to the user continuity contact during movement, that is why studies still ongoing the reduction of the negative effects which may weaken the performance of the network.

In cellular systems, the area which should be responsible for the provision of wireless services has a specific service provider, divided into small service areas each one of them called a cell. And they covered by the base station (BS), which in turn serve the mobile phone users known as mobile stations (MS) which located within that area by a wireless link. Cells are divided into groups, each group controlled by what called Mobile Switching Center (MSC). A fixed number of channels allocated to each base station and also ensure continuity of contact when the user moves from one cell to another neighboring cells, which interfere with each other [1], [2].

The process in which changing the channel (frequency, time slot, spreading code, or combination of them) associated with continuous contact during the user movement called handover process [3].

Channel in cellular systems can take based on the multiple access technique used fixed frequency bandwidth (FDMA), a specific time-slot within a frame (TDMA), or a particular code (CDMA) [2].

One of the most important mobile communication system issues is using spectrum efficiently, in other word using the same frequency channels for maximum possible by reusing the same channels in other cells to support the large number of synchronized calls. There are several strategies or schemas may use in spectrum management, the most important the fixed channel scheme, which is assigned a specific set of channels per cell. And the same set of channels can be reused in another cell, away first cell) to an appropriate distance (to ensure that there is no overlap between the channels or be accepted. This scheme is used in most cellular systems because it is simple, but there is a problem when the calls are increased more than the number of channels in the cell that cause the number of blocked calls becomes greater, and to reduce this problem they used the channel 
borrowing strategy which can able to borrow a channel from an adjacent cell to ensure that does not interfere with calls in that donor cell and this process is supervised by the mobile switching Center [4].

For load balancing in cellular systems (2G, 3G) and systems that are based on (code-division multiple access (CDMA). CDMA2000 and wideband code-division multiple access (WCDMA) uses a technique called cell breathing, which allows the cell to shrink the geography (reducing effective coverage area) when the traffic is high in the cell, it can redirect the traffic to the adjacent cell where low traffic. And the opposite happens when low traffic is expanding the cell [5], [6].

In mobile network the handover process is very important. It allows the call continuation with high mobility. However the handover increases the signaling load and increase the mobile Battery consumption.

Location based service offered a great opportunity for application development in the mobile field. Thus, in this paper location based algorithm will be developed which utilized the knowledge of the location to optimized the number of handover, then the algorithm will be tested by MATLAB simulation, physical model and a mathematical model can be developed to have a reliable, to reduce the number of the handover request so that the signaling load and mobile Battery consumption will be reduced.

\section{A. Definition and Type:}

\section{Background On Handover Process}

Handover is the process for changing the voice and control channels of a mobile station from one BS to another when the mobile station moves from one cell to another during the call [7]. Handover process it should need to be the least possible and when you need to complete the handover must be successful and not be sensible by the user [8]. There are many different factors may be depended on to classify the handover, one of these classifications the handover depended on a network type. If handover between similar network handover or (Point of Access) supporting the same network technology called horizontal, e.g. two geographically neighboring BSs of a $3 \mathrm{G}$ cellular network. Else if handover between different networks, so-called vertical handover e.g., an IEEE 802.11 AP and a 3G BS. [9], [1]. But in this paper, we focus attention for horizontal handover only that shown in Fig. 1

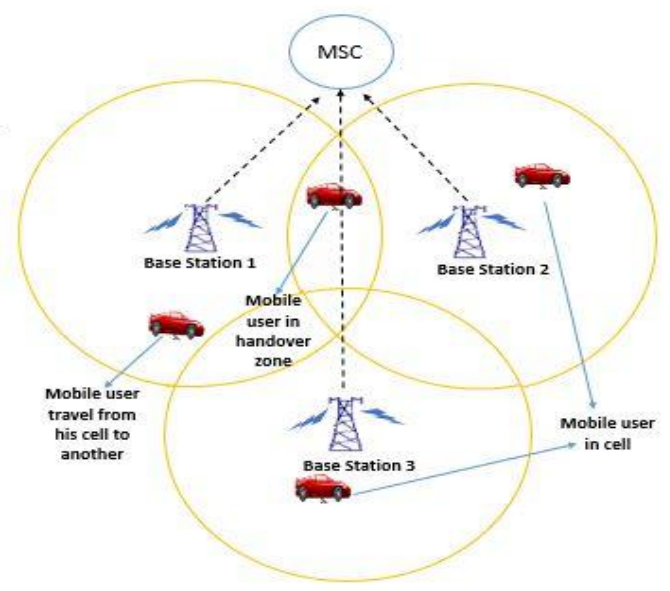

Fig. 1. Horizintal Handover

Can also classify handover to Hard handover and soft handover and this classification depends on the BSs that will serve the mobile station. [1].

- Hard handover : which occurs in different radio systems on the properties of the different radio link or it's called hard handover because the mobile station liberated from base station serviced before using the new base station candidate sources for handover [2], [3].

- Soft handover: This type of handover mobile station (MS) doesn't interrupt contact with the old base station until contact is to a new base station. And it can be related to the mobile station more than the base station [2], [3].

\section{B. Handover Decision}

Many strategies proposed are used to determine the need to implement a process of handover.

- Network Controlled Handover (NCHO): This method was used in the first generation of cellular communications systems and the network mobile telephone switching office (MTSO) is responsible for decisions handover address where measurements RSS (Received Signal Strength) and the time of implementation of the necessary handover process several seconds because the load on network High. 
- Mobile Assisted Handover (MAHO): In this strategy the mobile station is responsible for measurements of RSS and send them periodically to the base station and decide based upon the base station or caught when to begin the implementation of a handover. This strategy is used in the GSM network and the time of implementation of the process of handling $1 \mathrm{Sec}$. [8].

Mobile Controlled Handover(MCHO): Mobile Station continuously monitors the signals of the surrounding BSs and initiates the handover process when some criteria are met. (100-500ms) handover execution time [10].

\section{Pesrformance Metrics to make Handover Decision}

In the preceding paragraph, we noted how to decision-making in the handover process by the network and by the help of the mobile station. And decision making handover can also use the following performance indicators:

1. Call Blocking Probability: it's defined as the probability of blocking new calls resulting from higher base station traffic and lack of communication channels available.

2. Handover Request Probability: it's the possibility to send request for handover process before the end of the call.

3. Handover blocking Probability: its handover probability attempts which blocked

4. Handover Failure Probability: it's probability of mobile station connection to the new base station, but the handover is failing because of the receiver is inadequate.

5. Handover Delay: it's a delay of the handover process temporarily to the base station in a new cell can implementation (if there is a channel at the same time user access to cell can delay handover a certain period until a free communication channel). [7], [11].

\section{Related Work}

In recent times, a large amount of research work in improved techniques for delivery of cellular networks. In [12] Proposed an algorithm known as the LTE Hard Handover Algorithm with Average Received Signal Reference Power (RSRP) Constraint (LHHAARC) this algorithm are used to reduce the number of the handover in system and reduce delays. This algorithm was compared with three well-known algorithms to minimize handover by computer simulations and their results found that this algorithm outperforms them by giving the least amount of delay system less the handover of the system with improved system performance with maximum data transfer rate.

In [11] another study provided an enhanced version of self_optimizing algorithm, have been used to reduce the negative effects which result from the handover process such as handover failure and the ping Pong handover, and compared this algorithm with traditional algorithms indicate that compared to give improved results.

In [13] Proposed two schemes to improve handover in LTE networks depending on the location of the mobile station. The first scheme used to reduce the handover by expected the target cell to be handover process and the preparation for the process of handover. As the second scheme uses the mobile station location to calculate the best cell geography to complete the handover process and add parameter (RSRP) to reduce the number of handover when ((Time-to-Trigger (TTT) is small and if the (TTT) largest gives improved success rates.

In [14] Based on fuzzy logic this algorithm have been suggested and renamed Fuzzy controller for Handoff Optimization (FCHO) exploiting this algorithm features a number of available algorithms and found it removes the problem of critical impact as a result of the change in value (Threshold, hysteresis), depending on the change in (RSSI) and speed of the mobile station.

\section{A. Physical Model}

\section{Proposed (LBKHO) Algorithem}

The proposed model in this paper consists of three circular cells A, B and C the contiguous to simplify the process of clarifying the handling of the cells as shown in Figure 2 also shows the areas of handover, Handover zone1 between cells A and B and handover zone 2 between cells B and C, also it illustrates the cells extend by change the geography (increase effective coverage area) when to need it (cell breathing) . 


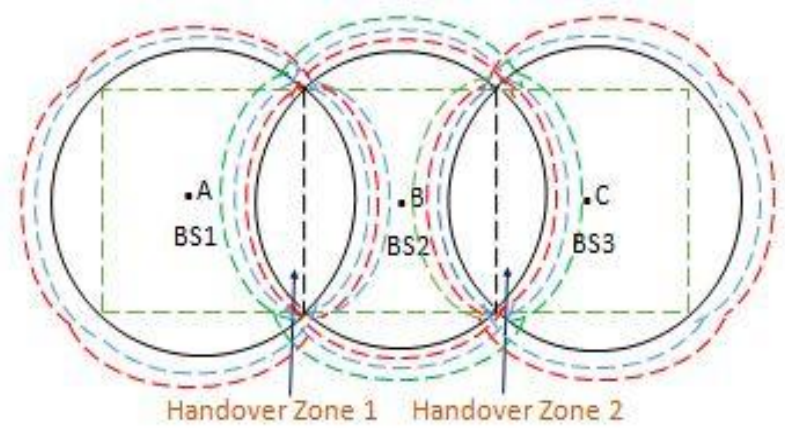

Fig. 2 Simulation Model

Assume that the window dimensions length $2 \mathrm{Km}$ each cell well as three cells becomes the length of the window $6 \mathrm{Km}$, and width $2 \mathrm{Km}$ represented in Figure (3) in the $\mathrm{x}$-axis and $\mathrm{y}$-axis, and assuming that the total number of users in cells 200 users distributors intracellular.

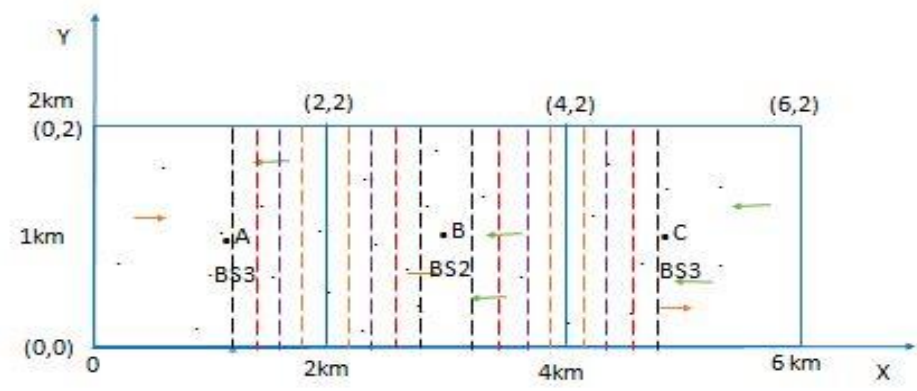

Fig. 3 Simulation Window

Take in this case the moving direction (D) either +1 or -1 , the primary location for mobile station $\left(\mathrm{X}_{0}, \mathrm{Y}_{0}\right)$ And determinate the zone of the handover request from $\left(\mathrm{X}_{\mathrm{hl}}-\mathrm{X}_{\mathrm{hh}}\right)$ And the cutoff point between the cells $X_{h}$ for each the neighboring cell at direction, moving mobile station show in Figure 4, the distance between $\mathrm{X}_{\mathrm{h}}$ and $\mathrm{X}_{\mathrm{hi}}$ It is (-delta), also $\mathrm{X}_{\mathrm{h}}$ And $\mathrm{X}_{\mathrm{hl}}$ It is (+delta).

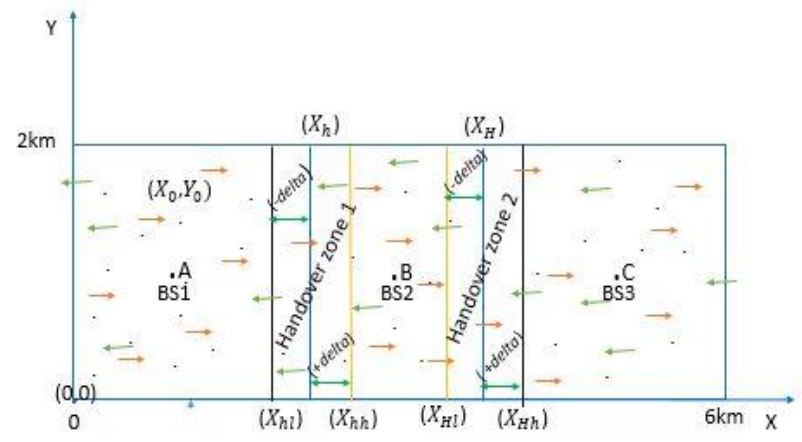

Fig.4 Handover Zone

\section{B. Mathematical Model}

For the application of the proposed model we used MATLAB to configure like environment real environment for users of mobile cellular systems. Using random generator function, we select a random location for users of mobile terminals in the model. And to generate calls to the users arrival times randomly used. We used Poisson distribution function because of the advantages it is simple, stable and independent in all moments of time. Poisson distribution gives the number of arrivals in a constant length ( $t$ ) distributed in the mean value $(\lambda t)[15]$, the following relationship

$$
P(x, t)=\frac{(\lambda t)^{x}}{x !} \cdot e^{-\lambda t}
$$

After making that environment through consideration of the physical model we can use the data to find less can receive user when the maximum distance it can travel without having to transfer it to the base station in 
the other cell. The greater the distance between transmitter and receiver is receiving power loss, this loss is called (free space loss) [8] which can be calculated through the following equation .

$$
\begin{aligned}
& \frac{P_{t}}{P_{r}}=\frac{(4 \pi f d)^{2}}{C^{2}} \\
& P_{r}=P_{t} \frac{C^{2}}{(4 \pi f d)^{2}}
\end{aligned}
$$

$\mathrm{Pt}=$ signal power at the transmitting antenna

$\mathrm{P}_{\mathrm{r}}=$ signal power at the receiving antenna

$\mathrm{f}=$ carrier frequency

$\mathrm{d}=$ propagation distance between antennas

$\mathrm{c}=$ speed of light $(3 \times 108 \mathrm{~m} / \mathrm{s})$

When $\mathrm{f}=900 \mathrm{MHZ}, \mathrm{Pt}=25 \mathrm{Watt}, \quad \mathrm{d}=2 \mathrm{~km}$. By using equ. 3 we can find the power receive $(\mathrm{Pr})$ $\mathrm{P}_{\mathrm{r}}=-53.56 \mathrm{dBm}$.

From the physical model we can calculate the mobile station's location and then make a decision about the necessity of handover through the results that we could get. Total displacement can be calculated from the equation (4), whenever mobile station's location is $\left(\mathrm{X}_{\mathrm{c}}, \mathrm{Y}_{\mathrm{c}}\right)$.

$\mathrm{t}_{\text {sim }} \equiv$ time of simulation clock

$$
\Delta \mathrm{d}_{\mathrm{T}}=\sum_{\mathrm{t}=0}^{\mathrm{t}=\mathrm{tsim}} \Delta \mathrm{d}_{\mathrm{t}}
$$

$\Delta \mathrm{d}_{\mathrm{T}} \equiv$ Total displacement

$\Delta \mathrm{d}_{\mathrm{t}} \equiv$ Average displacement

If $\mathrm{D}$ is equal to (+1), then the user movement during a call from left to right if the user moves either from cell $\mathrm{A}$ to cell $\mathrm{B}$ or from cell $\mathrm{B}$ to cell $\mathrm{C}$, if the location from which the call originated a specific point $\left(\mathrm{X}_{0}, \mathrm{Y}_{0}\right)$ And the average speed of movement of the user $\left(v_{\text {avg }}\right)$, and we can calculate the current location point $\left(\mathrm{X}_{\mathrm{c}}, \mathrm{Y}_{\mathrm{c}}\right)$ in any time by using equation $(5,6)$.

$$
\begin{aligned}
& \mathrm{X}_{\mathrm{c}}=\mathrm{X}_{0}+\Delta \mathrm{d}_{\mathrm{T}} \\
& \mathrm{y}_{\mathrm{c}}=\mathrm{y}_{0}+\Delta \mathrm{d}_{\mathrm{T}}
\end{aligned}
$$

Through history we find the average duration of user calls and is represented here by the symbol $(\tau)$ and using his time of current arrival call, we can find the remaining time to end the call (Rtc)

$$
\text { Rtc }=\text { arrival time }+ \text { call duration }(\tau) \quad(7)
$$

Using the average speed ( $v_{\text {avg }}$ ) of the user we can find the remaining estimate distance to the user travels to end call (Redc.)

$$
\operatorname{Redc}=\operatorname{Rtc} * v_{\text {avg }}
$$

During the movement of the user determines the current location at every update of the location if the current location $\left(\mathrm{X}_{\mathrm{c}}, \mathrm{Y}_{\mathrm{c}}\right)$ By equation $(5,6)$, if the movement $\mathrm{A}$ to $\mathrm{B}$.

If the movement $\mathrm{B}$ to $\mathrm{C}$

$$
\mathrm{X}_{\mathrm{c}}>\mathrm{X}_{\mathrm{hh}}
$$

$$
\mathrm{X}_{\mathrm{c}}>\mathrm{X}_{\mathrm{Hh}}
$$

To calculate the users current location's distance from base station has served, where the location of the base station is $\left(\mathrm{X}_{\mathrm{BS} 1}, \mathrm{Y}_{\mathrm{BS} 1}\right)$ In cell $\mathrm{A}$, use the following equation

$$
\mathrm{dBS}_{1}=\sqrt{\left(\mathrm{X}_{\mathrm{BS} 1}-\mathrm{X}_{\mathrm{c}}\right)^{2}-\left(\mathrm{Y}_{\mathrm{BS} 1}-\mathrm{Y}_{\mathrm{c}}\right)^{2}}(11)
$$

Also to calculate the users current location distance from base station has served, where the location of the base station is $\left(\mathrm{X}_{\mathrm{BS} 2}, \mathrm{Y}_{\mathrm{BS} 2}\right)$ In cell $\mathrm{B}$, use the following equation

$$
\mathrm{dBS}_{2}=\sqrt{\left(\mathrm{X}_{\mathrm{BS} 2}-\mathrm{X}_{\mathrm{c}}\right)^{2}-\left(\mathrm{Y}_{\mathrm{BS} 2}-\mathrm{Y}_{\mathrm{c}}\right)^{2}}(12)
$$

In this model the user is transferred to the other BS after the maximum distance can expand cell and symbolized for the maximum distance it can travel during this call without completion the handover process (mdc) to calculate the maximum distance the user can travel from $\mathrm{A}$ to $\mathrm{B}$ cell to an equation.

$$
\text { mdc }=\mathrm{dBS}_{1}+\mathrm{dr}
$$

From the previous equation can find (dr), it is the distance remaining to the user access to maximize distance.

$$
\mathrm{dr}_{1}=\mathrm{mdc}-\mathrm{dBS}_{1}
$$

Fig. 5 show how can calculate (dr) knowingly the (mdc) and (dBS) 


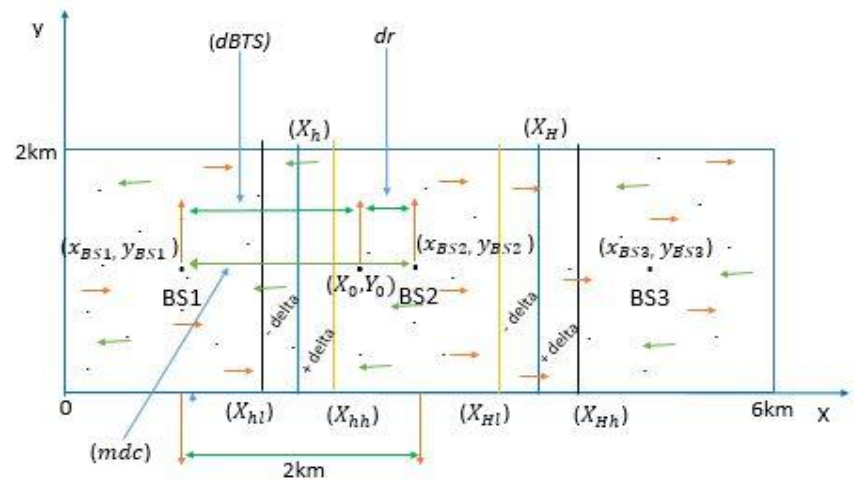

Fig. 5 How can calculate (dr)

That means, user's mobility is slow

$$
\mathrm{dr}_{1}>0
$$

$$
\text { Redc }>\mathrm{dr}_{1}
$$

$$
\mathrm{HOR}=1
$$

To complete the handover process the system to make sure there is unused channel in cell $\mathrm{B}$. Or HO $=1$

However, if the channel is not available in cell B fail handover, or $\mathrm{HO}=0$.

But in case

$$
\mathrm{dr}_{1}<0
$$

The user is high mobility so it is a necessary handover process, or handover is required, $\mathrm{HOR}=1$

To complete the handover process the system to make sure there is unused channel in cell $\mathrm{B}$. Or HO $=1$

However, if the channel is not available in cell $\mathrm{B}$ fail handover, or $\mathrm{HO}=0$

To calculate the maximum distance the user can travel from $\mathrm{B}$ to $\mathrm{C}$ cell to an equation.

$$
\text { mdc }=\mathrm{dBS}_{3}+\mathrm{dr}
$$

From the previous equation can find $(\mathrm{dr})$, it is the distance remaining to the user access to maximize distance.

If

$$
\mathrm{dr}_{3}=\mathrm{mdc}-\mathrm{dBS}_{3}
$$

That means, user's mobility is slow

$$
\mathrm{dr}_{3}>0
$$

$$
\text { Redc }>\mathrm{dr}_{3}
$$

The user is high mobility so it is a necessary handover process, or handover is required, HOR $=1$ To complete the handover process the system to make sure there is an unoccupied channel in cell $\mathrm{C}$. $\mathrm{HO}=1$ However, if the channel is not available in cell $\mathrm{C}$ fail handover, or $\mathrm{HO}=0$

But in case

$$
\mathrm{dr}_{3}<0
$$

The user is high mobility so it is a necessary handover process, or handover is required $(\mathrm{HOR}=1)$. To complete the handover process the system to make sure there is an unoccupied channel in cell $\mathrm{C}$.Or $(\mathrm{HO}=1)$. However, if the channel is not available in cell $\mathrm{C}$, handover is failed, or $(\mathrm{HO}=0)$

If $\mathrm{D}$ is equal to $(-1)$, then the user movement during a call from left to right if the user moves either from cell $\mathrm{B}$ tcell $\mathrm{A}$ or from cell $\mathrm{C}$ to cell $\mathrm{B}$, if the location from which the call originated a specific point $\left(\mathrm{X}_{0}, \mathrm{Y}_{0}\right)$ And the average speed of movement of the user $\left(v_{\mathrm{avg}}\right)$, and we can calculate the current location point $\left(\mathrm{X}_{\mathrm{c}}, \mathrm{Y}_{\mathrm{c}}\right)$ in any time by using equation $(23,24)$.

$$
\begin{aligned}
& \mathrm{X}_{\mathrm{c}}=\mathrm{X}_{0}-\Delta \mathrm{d}_{\mathrm{T}} \\
& \mathrm{Y}_{\mathrm{c}}=\mathrm{y}_{0}-\Delta \mathrm{d}_{\mathrm{T}}
\end{aligned}
$$

by using the same previous equations we can applying it when users moves from cell B to cell A, also in case $\mathrm{D}=-1$ which users moves from cell $\mathrm{C}$ to cell $\mathrm{B}$ with different in the equation characteristics according to user location in any cell, which instead of used equation (11) to calculate the user's current location distance from base station has served, e can used next equation to calculate the user's current location distance from base station (3) has served when users moves from $\mathrm{C}$ head toward cell $\mathrm{B}$

$$
\mathrm{dBS}_{3}=\sqrt{\left(\mathrm{X}_{\mathrm{BS} 3}-\mathrm{X}_{\mathrm{c}}\right)^{2}-\left(\mathrm{Y}_{\mathrm{BS} 3}-\mathrm{Y}_{\mathrm{c}}\right)^{2}}
$$


A. Simulation assumptions

\section{Simulation Scenario}

- Movement in X position only and Direction it either left or right. Assume that the movement direction is not changed during simulation.

- Base station position in the center of cell and we can determine the location by

- $\mathrm{BS}_{1}=(1000,1000), \mathrm{BS}_{2}=(3000,1000), \mathrm{BS}_{3}=(5000,1000)$.

Table I. below the list of parameters that was fixed during the simulations.

Table. I The Simulation parameter

\begin{tabular}{|c|c|c|}
\hline & Parameter & Value \\
\hline $1-$ & Number of users (MS) & 200 \\
\hline $2-$ & Power transmits $\mathrm{P}_{\mathrm{t}}$ & $25 \mathrm{Watt}$ \\
\hline $3-$ & Number of channels in each cell & 60 channels \\
\hline $4-$ & Average call duration & $180 \mathrm{~s}$ \\
\hline $5-$ & Simulation window width & $2000 \mathrm{~m}$ \\
\hline $6-$ & Simulation window length & $6000 \mathrm{~m}$ \\
\hline $7-$ & Simulation time & $200 \mathrm{~s}$ \\
\hline $8-$ & Distance between adjacent stations & $2000 \mathrm{~m}$ \\
\hline
\end{tabular}

\section{B. Flow chart}

The flow chart for the proposed algorithm, Location Based Knowledge Handover Optimization (LBKHO) algorithm is represented in Fig. 6

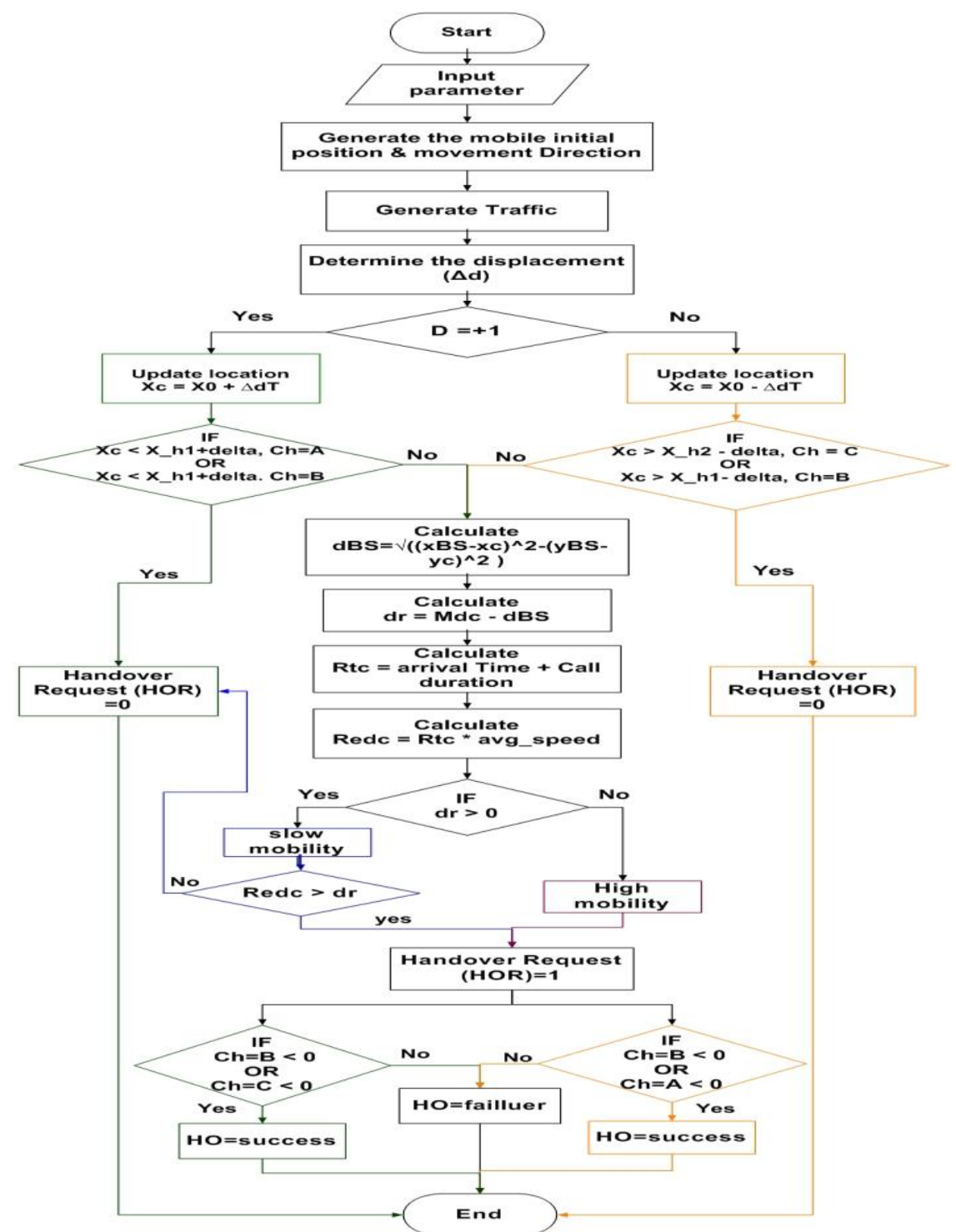

Fig. 6 flow chart represents a simulation scenario for (LBKHO) algorithm 


\section{Simulation Result:}

In the following, we present the results based on the simulation model described in the previous section .

Figure (7) illustrates the mobile user position in the cellular mobile system with random distribution, $\mathrm{X}$ axis represent length of simulation area (distance in meter), $\mathrm{Y}$ axis represent width of simulation area (distance in meter).

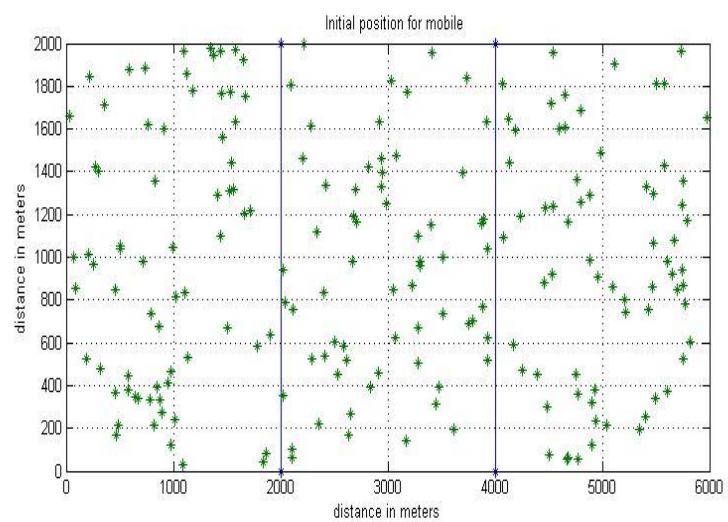

Fig.7.Initial position for mobile

Figure (8) shows the duration of (inter arrival) calls to mobile users in the proposed model, $\mathrm{X}$ axis represent mobile index, $\mathrm{Y}$ axis represent inter arrival time (s).

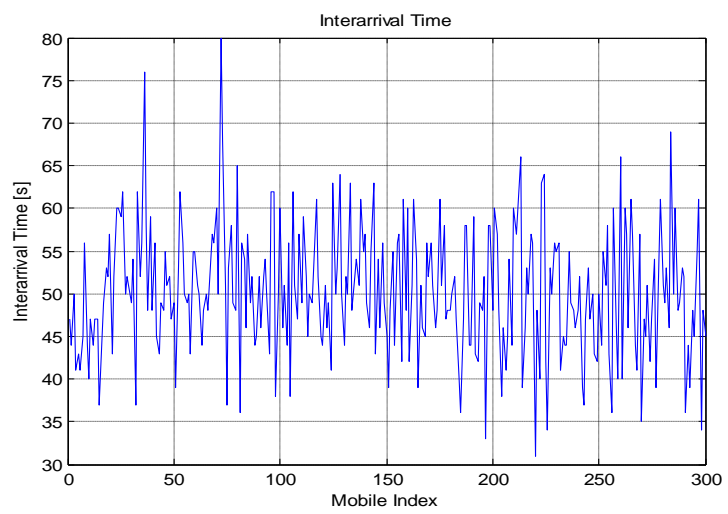

Fig. 8. Inter arrival Time

Figure (9) illustrates the call duration for users of mobile distributors randomly.

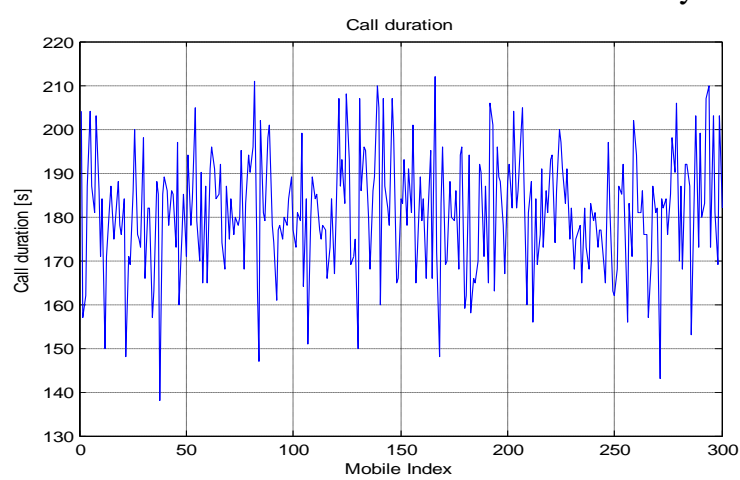

Fig. 9. Call duration

Figure (10) illustrates the relationship between the maximum distance can stretch out the cell and the number of requests for handover at different speeds to 5,10 and 15 meters and it is clear that the higher the (mdc) fewer handover requests. 


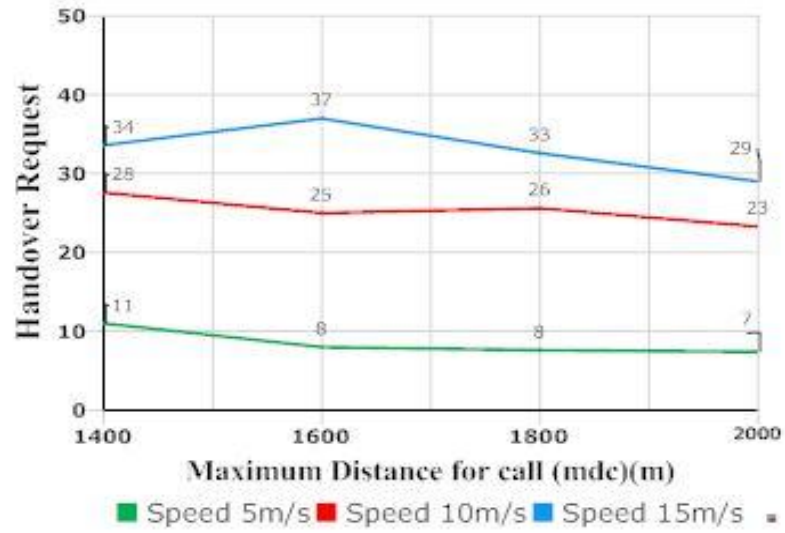

Fig. 10 Handover Request vs Maximam distance for call (mdc)

Figure (11) illustrates the relationship between average speed $(\mathrm{m} / \mathrm{s})$ and the number of handover requests, in addition to the number of requests which failed, and comparison of these results with the results of Adaptive Handover Initialization Region scenario [16] found that the number of handover requests in the proposed scenario became less.

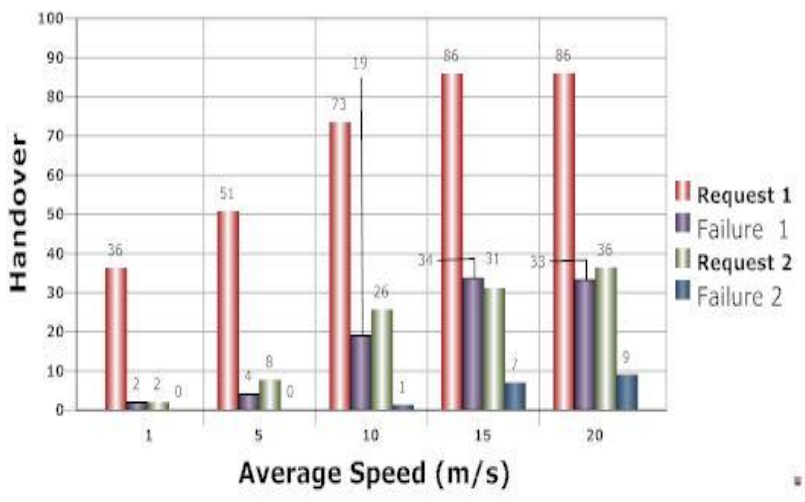

Fig . 11 Handover vs. Average Speed (m/s)

The relation between the number of handover requests and traffic of system observes from Fig.(12) note that when system traffic increase it followed by increase in number of handover requests.

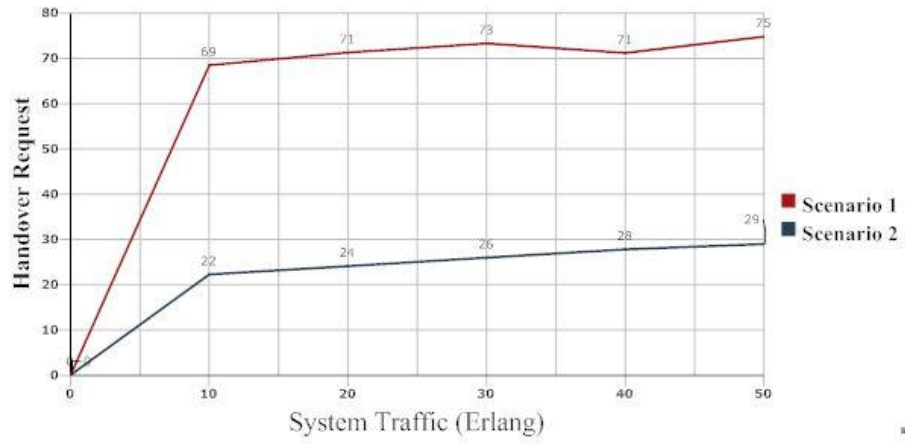

Fig. 12 Handover Request Vs. system traffic

figure 13 shows the relationship between the new call blocking and maximum distance for call (mdc) at different speeds 5,10 and $15 \mathrm{~m} / \mathrm{s}$, also through the figure we can observe, when speed is equal to $10 \mathrm{~m} / \mathrm{s}$ the number of new call blocking is greater than in the case of speed 5 and $15 \mathrm{~m} / \mathrm{s}$ when the (mdc) is equal to 1600 and 1800 . If the (mdc) is equal to 2000 the number of new call blocking more at speed $15 \mathrm{~m} / \mathrm{s}$ 


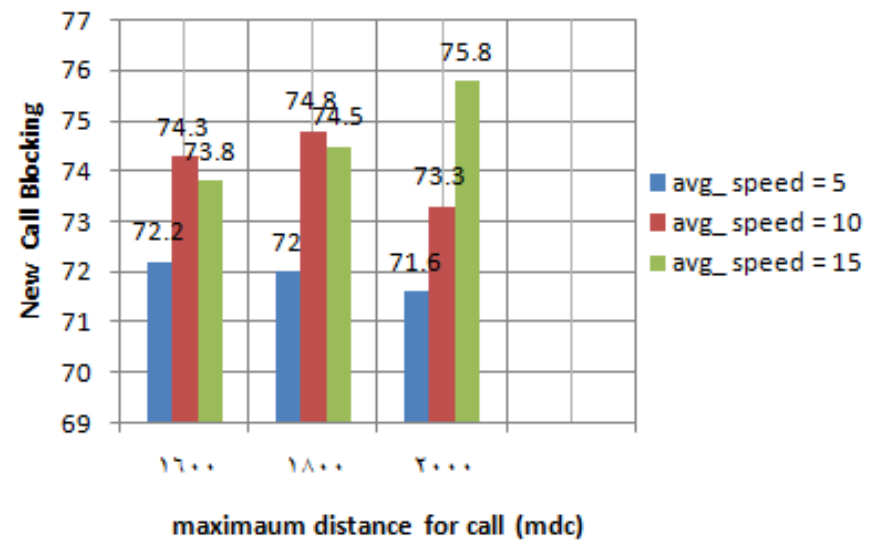

Fig. 13 New call blocking Vs. maximum distance for a call (mdc)

Table II : simulation result for (LBKHO) algorithm

\begin{tabular}{|c|c|c|c|c|c|c|}
\hline Average Speed & delta & $\mathrm{Mdc}$ & $\begin{array}{c}\text { New Call } \\
\text { Blocking(2) }\end{array}$ & $\begin{array}{l}\text { Handover } \\
\text { Request(2) }\end{array}$ & $\begin{array}{r}\text { Handover } \\
\text { Success }(2)\end{array}$ & $\begin{array}{l}\text { Handover } \\
\text { Failure(2) }\end{array}$ \\
\hline & & 1600 & 70.8 & 33.6 & 24.3 & 9.3 \\
\hline \multirow[t]{3}{*}{15} & 400 & 1800 & 71.1 & 33.6 & 24.6 & 9 \\
\hline & & 2000 & 74.1 & 31.6 & 25.6 & 7.5 \\
\hline & & 1600 & 71.8 & 37 & 27 & 8.1 \\
\hline \multirow[t]{3}{*}{15} & 500 & 1800 & 72.1 & 32.6 & 24.8 & 7.8 \\
\hline & & 2000 & 70 & 29 & 24 & 5 \\
\hline & & 1600 & 67.5 & 27.6 & 23 & 4.6 \\
\hline \multirow[t]{3}{*}{10} & 400 & 1800 & 70 & 26.6 & 23.6 & 3 \\
\hline & & 2000 & 75 & 25.3 & 23.3 & 2 \\
\hline & & 1600 & 75.2 & 25 & 22 & 3 \\
\hline \multirow[t]{3}{*}{10} & 500 & 1800 & 74.6 & 25.6 & 24.4 & 1.3 \\
\hline & & 2000 & 72.6 & 23.3 & 22.6 & 0.6 \\
\hline & & 1600 & 73.3 & 10.6 & 10.6 & 0 \\
\hline \multirow[t]{3}{*}{5} & 400 & 1800 & 72.3 & 9.5 & 9.5 & 0 \\
\hline & & 2000 & 70.1 & 8.8 & 8.8 & 0 \\
\hline & & 1600 & 75 & 8 & 8 & 0 \\
\hline \multirow[t]{2}{*}{5} & 500 & 1800 & 74.4 & 7.6 & 7.6 & 0 \\
\hline & & 2000 & 73.6 & 7.4 & 7.4 & 0 \\
\hline
\end{tabular}

Table. II represents the simulation results of (LBKHO) algorithm when system traffic is equal 30 Erlang.

\section{Conclusion}

In this paper, we proposed algorithm (LBKHO) which reduces the number of handover requests in the network, depending on knowledge of the location of the mobile station at each time update the mobile station location in the network.

From the results of the simulation algorithm MATLAB program through we shows that the higher in the (mdc), the number of handover requests less clearly at different speeds, and number of handover failure reduce too. In addition to, when system traffic increase it followed by an increase in the number of handover requests. Also, through the relationship between average speed $(\mathrm{m} / \mathrm{s})$ and the number of handover requests, in addition to the number of requests which failed, we found when the average speed increased the number of a handover requests and a handover failure increased too. And comparison of these results with the results of "Adaptive Handover Initialization Region" scenario. According to the previous results we found that, based on knowledge of the mobile station location, the number of handover request and handover failure will be reduced and the network performance will be improved.

\section{References}

[1]. [1] A. Sgora and D. D. Vergados, "Handoff prioritization and decision schemes in wireless cellular networks: a survey," vol. 11, no. 4,October 2009

[2]. P. Patnaik, "Fuzzy assisted handoff algorithm for micro and macro cellular system," Master, National Institute of Technology, Department of Electronics \& Communication Engineering National Institute of Technology, Rourkela Orissa, India, may 2010.

[3]. S. A. Mawjoud, "Simulation of handoff techniques in mobile cellular networks," vol. 15, no. 4, December 2007, pages 31-39. 
[4]. D. Sudarshan Subhashrao Sonawane and Dr.A.K.Sachan, "Channel allocation scheme in cellular system," Advanced Networking and Applications, vol. 2, pp. 452-457, June 2010.

[5]. K. J. V. M. L. Q. Paramvir Bahl, Mohammad T. Hajiaghayi and A. Saberi, "Cell breathing in wireless lans: Algorithms and evaluation,"Mobile Computing, IEEE Transactions, vol. 6, no. 2, pp. 164 - 178, February 2007.

[6]. T. Dollente, "cell breathing," search mobile computing, September $2005 . \quad$ [Online]. Available:http://searchmobilecomputing.techtarget.com

[7]. W. Stallings, Wireless communication and Network,, 2nd ed., C. W. Networks, Ed., New Jersey, 2005.

[8]. T. S. Rappaport, Wireless Communications Principles and Practice, 2nd ed., New Jersey, 2002.

[9]. S. S. S. Pallavi Shital Yevale, "A survey of vertical handoff algorithms to minimize probability of false handoff," International Journal of Engineering Research and Applications (IJERA), vol. 3, no. 1, pp. 96-105, January 2013.

[10]. S. K. Nasf Ekiz, Tara Salih and K. Fidanboylu, "An overview of handoff techniques in cellular networks," International Journal of Computer, vol. 1, no. 6, pp. 1716-1719, june 2007.

[11]. B. S. I. M. T. K. Irina Balan1, Thomas Jansen2, "Enhanced weighted performance based handover optimization in lte," EURASIP Journal on Wireless Communications and Networking, pp. 1 - 8, September 2011

[12]. H. A. M. R. Cheng-Chung Lin, Kumbesan Sandrasegaran and R. Basukala, "Optimized performance evaluation of lte hard handover Algorithm average rsrp constraint," vol. 3, no. 2, April 2011, pages 1-16.

[13]. P. F. Ming FEI, "Position-assisted fast handover schemes for lte-advanced network under high mobility scenarios," vol. 20, no. 4, December 2012, pages 268-273.

[14]. P. Dhand and P. Dhillon, Eds., Handoff Optimization for Wireless and Mobile Networks using Fuzzy Logic, vol. 63, no. 14, International Journal of Computer Applications, February 2013, pages. 31-35.

[15]. V. B. Iversen, "Teletraffic engineering and network planning," Technical University of Denmark, Technical University of Denmark Building 343, May 2010. [Online]. Available: http://www.fotonik.dtu.dk

[16]. A. B. A. Nagwan Abdel-wahab Mohamed Khair, Ashraf Gasim Elsid, "Adaptive handover initialization region," International Journal of Engineering and Technical Research (IJETR), vol. 2, no. 9, pp. 5-9, August 2014. [Online]. Available: www.erpublication.org 